\title{
Contribution of the E-Portfolio to the Improvement of Students' Performance: Results from a Pilot Survey in the Second Grade of Primary School in Greece
}

\author{
Basiliki Zafiropoulou ${ }^{1} \&$ Maria Darra ${ }^{2}$ \\ ${ }^{1}$ Primary School Teacher, Med Education Sciences, University of the Aegean, Rhodes, Greece \\ ${ }^{2}$ Department of Primary School Education, University of the Aegean, Rhodes, Greece \\ Correspondence: Maria Darra, Department of Primary School Education, University of the Aegean, Rhodes, \\ Greece.
}

Received: March 25, 2019

doi:10.5539/ies.v12n7p119
Accepted: April 29, 2019 Online Published: June 29, 2019

URL: https://doi.org/10.5539/ies.v12n7p119

\begin{abstract}
The purpose of this paper is to investigate the contribution of the electronic portfolio (e-portfolio) to improving students' performance and the sustainability of their knowledge. The method used is the experiment with an experimental and a control group, and a pair of pre and post measurements. The survey was carried out during the first trimester of the 2016-2017 school year and its duration was 30 teaching hours. The sample consisted of 40 pupils of the second grade of primary school in the city of Rhodes. The findings of the survey show that the students of the experimental group who used the e-portfolio scored higher in all assessments and managed to maintain the knowledge they achieved by scoring higher results in the second assessment of the material fifteen days later, compared to the students in the control group who used the traditional printed portfolio and scored lower in their performance ratings.
\end{abstract}

Keywords: authentic assessment, student assessment, e-portfolio, students' performance, primary education

\section{Introduction}

The Electronic Portfolio (e-portfolio), the digital version of the traditional portfolio, is a new approach to authentic assessment (Barrett \& Knezek, 2003), based on Information and Communication Technology (ICT) and falls into the category of alternative forms of assessment (Barrett, 2000).

Several researches have been carried out regarding the e-portfolio, both in theoretical approaches and in practical applications at all levels of education. There are many institutions and organizations around the globe (e-portfolios, e-portfolio California, e-portfolios Australia) working with the e-portfolio and its application by conducting numerous studies in cooperation with researchers (Ritzhaupt, Singh, \& Seyferth, 2008), universities, colleges and schools in all levels of education. The majority of those surveys concern higher education and the practical application of the e-portfolio to college and university students (Knight, Hakel, \& Gromko, 2006; Coutinho \& Bottentuit, 2008). There are also relative studies surveys addressed to teachers.

In the Greek educational reality, the surveys carried out are smaller in number and limited in range. More specifically, these surveys focus on the theoretical approach of e-portfolio, software as well as applications for e-portfolio development (Stylianou, 2013). There are also researches that record the beliefs and attitudes of educators (Paroutsas, 2011), and primary school students regarding the utilization of the traditional portfolio (Tsoutstou \& Bertsou, 2013), as well as surveys conducted to students of primary education, where the e-portfolio was implemented, but also to students of secondary education. Finally, there are researches concerning both teachers of primary education, and teachers of secondary education (Fotopoulou, 2012). In Greece, the studies about the use of the e-portfolio in the educational process through activities in the classroom are very limited. There is, therefore, a limited amount of research on the incorporation of the e-portfolio in the educational process in Greece, which also doesn't revolve around language courses.

This survey has been carried out aiming to fill this gap and specifically to explore the contribution of electronic student portfolio (e-portfolio), in the teaching of the course of Greek language in the second grade of primary school. Specifically, this paper aims to explore the contribution of the e-portfolio to improving student 
performance and the sustainability of their acquired knowledge. The results given throughout its course will highlight an alternative aspect of the use of technology in the educational process. Hopefully, it will encourage researchers to explore its further use in other teaching subjects and inform teachers about new possibilities of technology in education so as to be motivated to optimize it.

\section{Theoretical Framework}

The e-portfolio is an alternative form - method of student assessment. The main alternative forms of assessment according to Brown (1998) are: a) authentic assessment, b) self-assessment, c) portfolio-e-portfolio, d) descriptive assessment. Many writers refer to methods (not in forms of alternative assessment) such as (Tsagari, 2011): calendars, group projects, external evaluation, systematic observation, dramatization, storytelling, consultative meetings, and exchange of opinions.

According to Ryan (1994), portfolios are probably the most popular method of authentic assessment. Authentic assessment, unlike the traditional method, is used to evaluate each student individually. The student's work is compared with his previous work, not with the work of others, to measure improvement and progress. Students' authentic work samples are collected to serve as indicators of their improvement and progress. They are authentic as they represent the application and not the mere acquisition of knowledge and skills. In order to have an accurate assessment, we need some samples of different kinds that are collected at different times of the year. The deductions based on student samples are limited by the quality and quantity of the collected material. A single test, or a single observation, or a student's assignment, cannot capture the lasting, multidimensional, interactive requirement of authentic evaluation (Valencia, 1994, as reported in Ryan, 1994, p.2).

The e-portfolio is based on the following core principles (Abrami \& Barrett, 2005): a) learner-centered active learning, reflection, development of metacognitive skills, b) development of students' interest in New Technologies, c) increased responsibility, documentation and organization of their work, d) emphasis on integrated and experiential learning. All the above are intended to support a range of pedagogical processes and to facilitate assessment, while developing self-assessment and external assessment of students (Abrami \& Barrett, 2005).

The e-portfolio is distinguished in three main types, depending on the use and purpose it serves in education: assessment, showcase and developmental. In order for an e-portfolio to be successful, a set of criteria should be set out from the beginning to be followed throughout the implementation process. The model used is mainly the ADDIE model (Analysis, Design, Development, Implementation, Evaluation) (Abrami \& Barrett, 2005).

The utilization of e-portfolio offers multiple advantages to those involved in this process. As to the students, the e-portfolio: a) enables to change their passive role allowing them to participate more decisively in the process of teaching, learning and assessment (Canada, 2002), b) stimulates their interest, since they are familiar with new technologies and can easily meet the requirements of organization and management, c) enhances the confidence of the student, after he/she takes control of the learning (Sherry \& Barrett, 2005), d) is characterized by the flexibility and adapts to the needs, interests, and specific skills of the student (Love \& Cooper, 2004; Abrami \& Barrett, 2005), e) it does not confine learning in the classroom, since students can also use it in their free time (Health, 2005), f) enhances the teacher-student collaboration (Abrami \& Barrett, 2005), g) promotes a student-centered way of learning), h) strengthens the process of feedback, since it is a space of interaction, exchange of views, assessment and self-assessment, i) enhances cooperative learning and helps develop communicative skills (Abrami \& Barrett, 2005). In terms of teachers, the e-portfolio: a) provides a fuller image for each student (Love \& Cooper, 2004), b) is a more effective tool for assessing pupil's skills and knowledge (Barrett, 2000; Health, 2005) c) facilitates the announcement of the student's performance (Wade, Abrami \& Sclater, 2005) d) the cost of creation and management ranges from minimal to zero (Health, 2005). Regarding parents, the e-portfolio provides meaningful and understandable information on the progress of their children's learning (Strudler \& Wertzel, 2005) and is a better basis for discussion between the teacher and the parent.

On the other hand, many criticize the e-portfolio stating the following main drawbacks: a) The e-portfolio requires specialized knowledge on New Technologies. b) It is a laborious and time-consuming process. Reviewing as well as the final evaluation require a lot of time (Galanou, 2007). c) Logistic infrastructure and software upgrade are necessary (Health, 2005). d) There is a risk that students will be evaluated more about their technological knowledge and less about their skills. e) There is a number of key issues such as how to manage data, who will have access to the folder (Young, 2002), how to protect the copyrights and intellectual property of the students (Challis, 2005). f) There cannot be a single assessment guide for the e-portfolio (Galanou, 2007). There is a question of reliability of the evaluation, as well as a difficulty in evaluating e-portfolios (Linn \& Gronlund, 2000).

Nowadays, there are many tools and software to create an e-portfolio. Siemens (2004) developed a five-level model that defines the function and requirements of learning software. The first level includes simple web pages, 
blogs, wikis (static pages with limited access to their content). The second level includes dynamic websites that offer search and navigation capabilities. The third level includes the requirements and needs of an institution as well as the supporting structures for organization and operation. The fourth level includes the development and maintenance of the e-portfolio. The fifth level includes software applications, which are part of an academic systems network. It is worth mentioning that the Greek School Network (GSN) offers the teachers enrolled in the services to create an e-portfolio with the help of Mahara software.

\section{Main Purpose and Research Questions}

The main purpose of this study, which is part of a wider research effort, is to explore the use of the e-portfolio as an alternative form of teaching and authentic assessment of learning in primary education. In particular, the work aims to explore the contribution of the student's electronic portfolio so as to improve the students' performance and the sustainability of their knowledge.

The research questions this paper will attempt to answer are the following:

1st: To what extent does the electronic portfolio contribute to improving student performance?

2nd: To what extent does the electronic portfolio contribute to the sustainable acquisition of students' knowledge?

\section{Method-Sample}

The sample of the survey consisted of forty (40) pupils of the second class of the $1^{\text {st }}$ Experimental Primary School of Rhodes. The sample was twenty boys (50\%) and twenty girls (50\%), aged between 7 and 8 years old.

The method used is the experiment with an experimental and a control group, and a pre and post measurement. The survey was conducted during the first quarter of the 2016-2017 school year, namely from 19 September 2016 until 9 December 2016 and its duration was 30 teaching hours. The e-portfolio was incorporated in the teaching and evaluation of the Greek Language course in the second grade of Primary School. The 40 subjects formed two groups of twenty people. Group A was the experimental group, in which the students used the electronic portfolio (e-portfolio) and group B was the control group, in which students used the traditional printed portfolio.

Regarding data collection tools, evaluation tools were used for all eight units of the Language Course (2nd grade, Language, 1st Issue) and a retesting of the last follow-up assessment of the 8th Greek Language Unit after a period of (15) days. The printed assessment tool, the repeat test, was designed with to be conducted after the completion of each teaching unit. It included exercises of various types that were based on the objectives of each unit in the content of the $2^{\text {nd }}$ Grade Greek Language Course. A total of 8 units were evaluated. The results of the printed assessment tool were counted on a scale of 100 .

\section{Data Collection and Analysis}

Microsoft Excel spreadsheet software and Statistical Package for the Social Sciences (SPSS) statistics 21.0 were used to process data and generate results.

The research data analysis was carried out on two levels, initially with the descriptive analysis and then with the inductive analysis. At the stage of descriptive statistical analysis, frequency distribution tables are given for the case of nominal variables. For quantitative variables the statistical average score was used to measure central tendency and the standard deviation as a dispersion measure. On the same stage, there was also conducted a control of regularity with the statistical criterion Shapiro-Wilks (sample $<50$ persons), to decide the use of the statistical criterion for checking the statistical significance of the differences, depending on the existence or not of normal distribution.

On the induction statistic stage, the following statistical criteria were applied depending on the case and the stage of experimental research (Andreadakis, 2006):

Comparison of rates in the scores:

The statements of students and teachers were audited in order to compare and evaluate the quality of self-assessment, where the independent variable is a categorical variable with two positions (Control Group and Experimental Group) and the dependent variables are quantitative. The t-test criterion was applied for independent samples, in cases where the distribution is normal and the Mann-Witney criterion for the rest of them.

In the case of the eighth and follow-up measurement of the Experimental Group students, in which the results of the same students were measured twice (multiple measurements), the non-parametric Wilcoxon criterion was applied as the values of the two measurements did not follow the normal allocation. 


\section{Research Process}

The e-portfolio was used in the context of the evaluation of the Greek Language course in the Second Grade of Primary School. The participants were students of the 1st Experimental Primary School of Rhodes, in which the researcher has an established post and has been working there the last 6 years. Both classes of the school's second grade participated in the survey. The experimental group consisted of the B2 class students, where the researcher is teaching, and B1 class students were the control group.

The teaching of each unit of the language course took from one to one and a half weeks. The units taught were eight in total. The students filled out the repeat tests after the completion of each unit. The experimental group used the e-portfolio as a storage medium of the printed test that was scanned and saved in it and the control group used the printed portfolio. Because the age of the students -7 years old- would be restrictive in the process of creating their personal electronic portfolios, the researcher and teacher created folders in dropbox and shared them with parents and students. Each student had his/her own portfolio. The students and their parents were able to access the folder and its content at any time. The examinations of the students in the units were carried out on the following dates (Table 1):

Table 1. Examined units per test date

\begin{tabular}{ll}
\hline $1^{\text {st }}$ unit Student Book (S.B.) $-27 / 9 / 2016$ & $5^{\mathrm{TH}}$ unit S.B. $-16 / 11 / 2016$ \\
$2^{\text {nd }}$ unit S.B. $-4 / 10 / 2016$ & $6^{\mathrm{TH}}$ unit S.B. $-28 / 11 / 2016$ \\
$3^{\mathrm{RD}}$ unit S.B. $-11 / 10 / 2016$ & $7^{\mathrm{TH}}$ unit S.B. $-31 / 10 / 2016$ \\
$4^{\mathrm{TH}}$ unit S.B. $-21 / 10 / 2016$ & $8^{\mathrm{TH}}$ unit S.B. $-9 / 12 / 2016$ \\
\hline
\end{tabular}

After the evaluation was completed in all 8 units, after two weeks, both teams have retaken the last test (8th) in order to check the degree of differentiation as to the sustainability of knowledge.

\subsection{Design of Proposed Educational Activity}

Creating the student's electronic portfolio is the most important element of the educational activity. In this study, students, due to their young age, aged 6-7, created their own electronic portfolio with the help and support of their parents. Their folder included their follow-up tests, as well as other material related to the language course.

Table 2. Description of proposed educational activity

\begin{tabular}{|c|c|}
\hline \multicolumn{2}{|c|}{ Description of proposed educational activity } \\
\hline Title of educational activity & Creation of electronic portfolio \\
\hline \multicolumn{2}{|l|}{ Educational framework } \\
\hline Educational challenge & $\begin{array}{l}\text { The assessment relates not only to the knowledge acquired by students but also to the values, } \\
\text { attitudes and skills they acquire through the learning process. Using the e-portfolio will give } \\
\text { the learner the opportunity to participate actively in the learning process, while students will } \\
\text { have the opportunity to choose and show subjects/materials directly related to their progress. } \\
\text { The e-portfolio is a collection of students' objects where they can evaluate their potential } \\
\text { and their shortcomings-weaknesses through the work they save and organize. } \\
\text { Using the e-portfolio: }\end{array}$ \\
\hline \multirow[t]{2}{*}{ Questions to investigate } & Does it help students to improve their performance? \\
\hline & Does it help students to retain the knowledge they have acquired? \\
\hline \multirow{8}{*}{ Student Characteristics } & Cognitive: \\
\hline & The students: \\
\hline & Are not familiar with the software's applications \\
\hline & They are well acquainted with the computer and the Internet \\
\hline & Psychosocial: \\
\hline & Students are quite eager to participate in the educational process \\
\hline & Demographical: \\
\hline & The trainees are 6-7 years old and both sexes are equally represented. \\
\hline
\end{tabular}




\subsection{Design and Schedule of Implementation of Educational Activities}

The following Table 3 presents the design and timetable for the implementation of educational activities.

Table 3. Design and schedule of implementation of educational activities

\begin{tabular}{|c|c|c|}
\hline Date & Teaching hours & Activities \\
\hline 19 September & 1 teaching hour & $\begin{array}{l}\text { Filling out of the initial questionnaire - joint group activity of the } \\
\text { control group and the experimental group. Introduction to Dropbox }\end{array}$ \\
\hline 21 September & 2 teaching hours & \multirow{2}{*}{ Parents briefing and creation of individual folders for each child } \\
\hline 22 September & 1 teaching hour & \\
\hline 26 September & 2 teaching hours & $1^{\text {st }}$ repeat test and filling out of evaluation table \\
\hline 28 September & 1 teaching hour & Update and arranging of individual e-portfolios \\
\hline 4 October & 2 teaching hours & $2^{\text {nd }}$ repeat test and filling out evaluation table \\
\hline 6 October & 1 teaching hour & Update and arranging of individual e-portfolios \\
\hline 11 October & 2 teaching hours & $3^{\text {rd }}$ repeat test and filling out evaluation table \\
\hline 14 October & 1 teaching hour & Update and arranging of individual e-portfolios \\
\hline 21 October & 2 teaching hours & $4^{\text {th }}$ repeat test and filling out evaluation table \\
\hline 25 October & 1 teaching hour & Update and arranging of individual e-portfolios \\
\hline 31 October & 2 teaching hours & $7^{\text {th }}$ repeat test and filling out evaluation table \\
\hline 2 November & 1 teaching hour & Update and arranging of individual e-portfolios \\
\hline 16 November & 2 teaching hours & $5^{\text {th }}$ repeat test and filling out evaluation table \\
\hline 18 November & 1 teaching hour & Update and arranging of individual e-portfolios \\
\hline 28 November & 2 teaching hours & $6^{\text {th }}$ repeat test and filling out evaluation table \\
\hline 30 November & 1 teaching hour & Update and arranging of individual e-portfolios \\
\hline 9 December & 2 teaching hours & $8^{\text {th }}$ repeat test and filling out evaluation table \\
\hline 12 December & 1 teaching hour & Update and arranging of individual e-portfolios \\
\hline 14 December & 1 teaching hour & $8^{\text {th }}$ repeat test (follow-up) \\
\hline 16 December & 1 teaching hour & $\begin{array}{l}\text { Filling out of the final questionnaire - joint group activity of the } \\
\text { control group and the experimental group. }\end{array}$ \\
\hline
\end{tabular}

\section{Results}

Contribution of the e-portfolio to improving students' performance and retaining their knowledge (1st and 2nd research questions)

Analyzing research data obtained from the rubrics and the scores of students, we compared the scores between the two groups to determine, if and to what extent, the students of the experimental group gathered better scores than their peers in the control group.

The comparison of the differentiations in the average scores of students from both groups was made based on the Mann-Witney statistical criterion (because the values of the score variables do not follow the normal distribution, Shapiro-Wilk sig. <.050).

The analysis of the data shows that all eight scores of the experimental group students are better than those of the control group students, even though some differences are not statistically significant. Indicatively, the greatest differences occurred in order of significance in the 4th rating $(+20.08 \% \mathrm{U}(40)=-2.818, \mathrm{p}=.005)$ in the 8 th rating $(+16.13 \% \mathrm{U}(40)=-3.987, \mathrm{p}=.000)$, the 1 st rating $(+13.14 \% \mathrm{U}(40)=-2.184, \mathrm{p}=.029)$ and the 3rd rating $(+11.82 \% \mathrm{U}(40)=-3,605, \mathrm{p}=, 000)$. On the contrary, the smallest difference was measured in the 7 th rating of both groups $(+1.78 \%, \mathrm{U}(40)=-1.114, \mathrm{~ns})$. 
Table 4. Scores of the students of both groups

\begin{tabular}{|c|c|c|c|c|c|c|c|}
\hline Score & Group & $\bar{X}$ & $\mathrm{Sd}$ & $\operatorname{diff}(\%)$ & $\mathrm{U}$ & $\mathrm{df}$ & $\mathrm{p}$ \\
\hline \multirow{2}{*}{ 1st score } & Experimental & 87.75 & 11.030 & \multirow{2}{*}{13.14} & \multirow{2}{*}{-2.184} & \multirow{2}{*}{38} & \multirow{2}{*}{.029} \\
\hline & Control & 77.56 & 16.959 & & & & \\
\hline \multirow{2}{*}{$2^{\text {nd }}$ score } & Experimental & 88.60 & 13.000 & \multirow{2}{*}{2.14} & \multirow{2}{*}{-1.070} & \multirow{2}{*}{38} & \multirow{2}{*}{ s } \\
\hline & Control & 86.74 & 13.816 & & & & \\
\hline \multirow{2}{*}{$3^{\text {rd }}$ score } & Experimental & 95.05 & 4.371 & \multirow{2}{*}{11.82} & \multirow{2}{*}{-3.605} & \multirow{2}{*}{38} & \multirow{2}{*}{.000} \\
\hline & Control & 85.00 & 9.580 & & & & \\
\hline \multirow{2}{*}{$4^{\text {th }}$ score } & Experimental & 90.30 & 8.797 & \multirow{2}{*}{20.08} & \multirow{2}{*}{-2.818} & \multirow{2}{*}{38} & \multirow{2}{*}{.005} \\
\hline & Control & 75.20 & 19.525 & & & & \\
\hline \multirow{2}{*}{$5^{\text {th }}$ score } & Experimental & 89.15 & 9.074 & \multirow{2}{*}{2.04} & \multirow{2}{*}{-0.493} & \multirow{2}{*}{38} & \multirow{2}{*}{ s } \\
\hline & Control & 87.37 & 12.742 & & & & \\
\hline \multirow{2}{*}{$6^{\text {th }}$ score } & Experimental & 89.25 & 8.503 & \multirow{2}{*}{1.87} & \multirow{2}{*}{-0.718} & \multirow{2}{*}{38} & \multirow{2}{*}{ s } \\
\hline & Control & 87.61 & 6.242 & & & & \\
\hline \multirow{2}{*}{$7^{\text {th }}$ score } & Experimental & 82.95 & 11.311 & \multirow{2}{*}{1.78} & \multirow{2}{*}{-1.114} & \multirow{2}{*}{38} & \multirow{2}{*}{ ns } \\
\hline & Control & 81.50 & 8.241 & & & & \\
\hline \multirow{2}{*}{$8^{\text {th }}$ score } & Experimental & 92.15 & 8.506 & \multirow{2}{*}{16.13} & & 8 & \\
\hline & Control & 79.35 & 8.750 & & 1 & 38 & \\
\hline
\end{tabular}

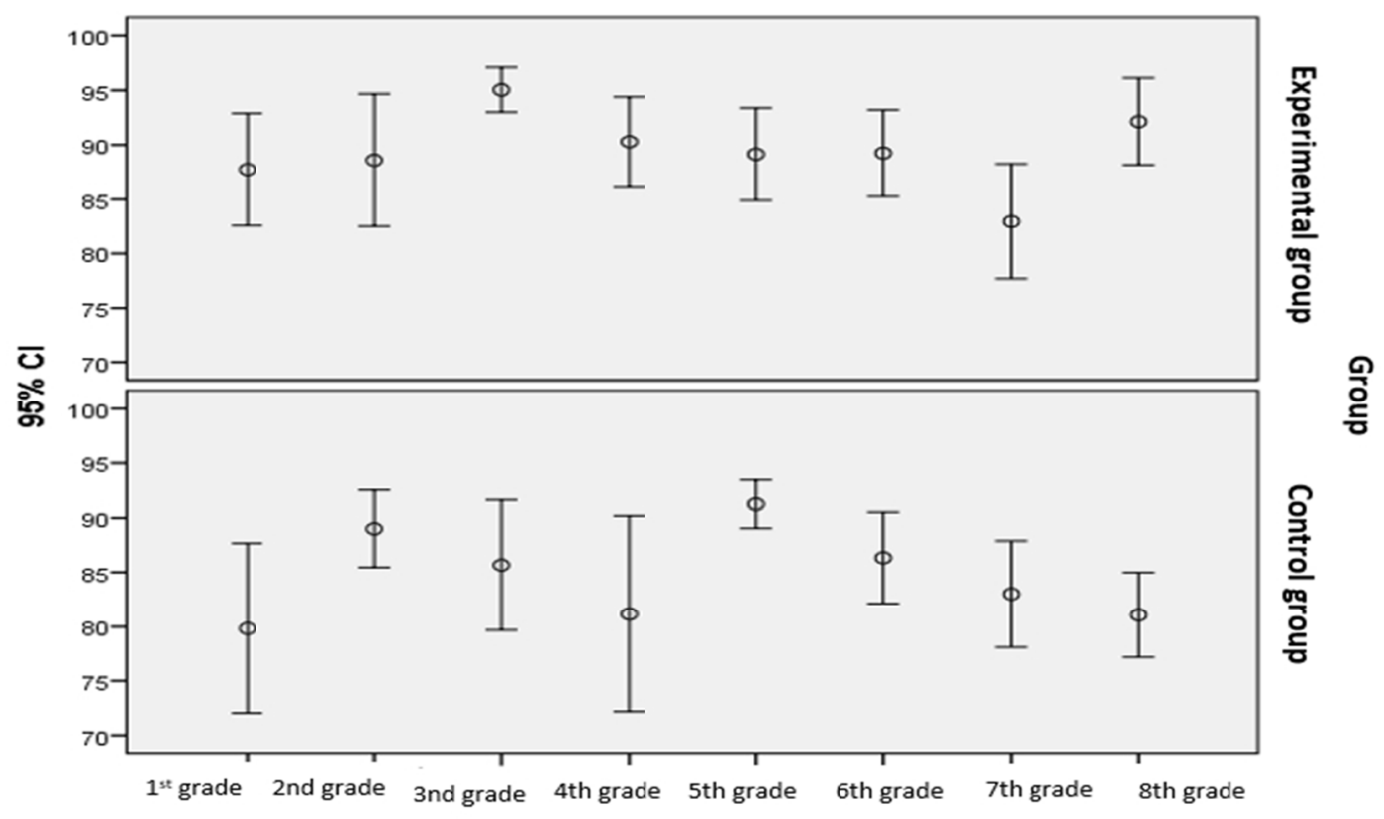

Figure 1. Scores of the students of both groups 


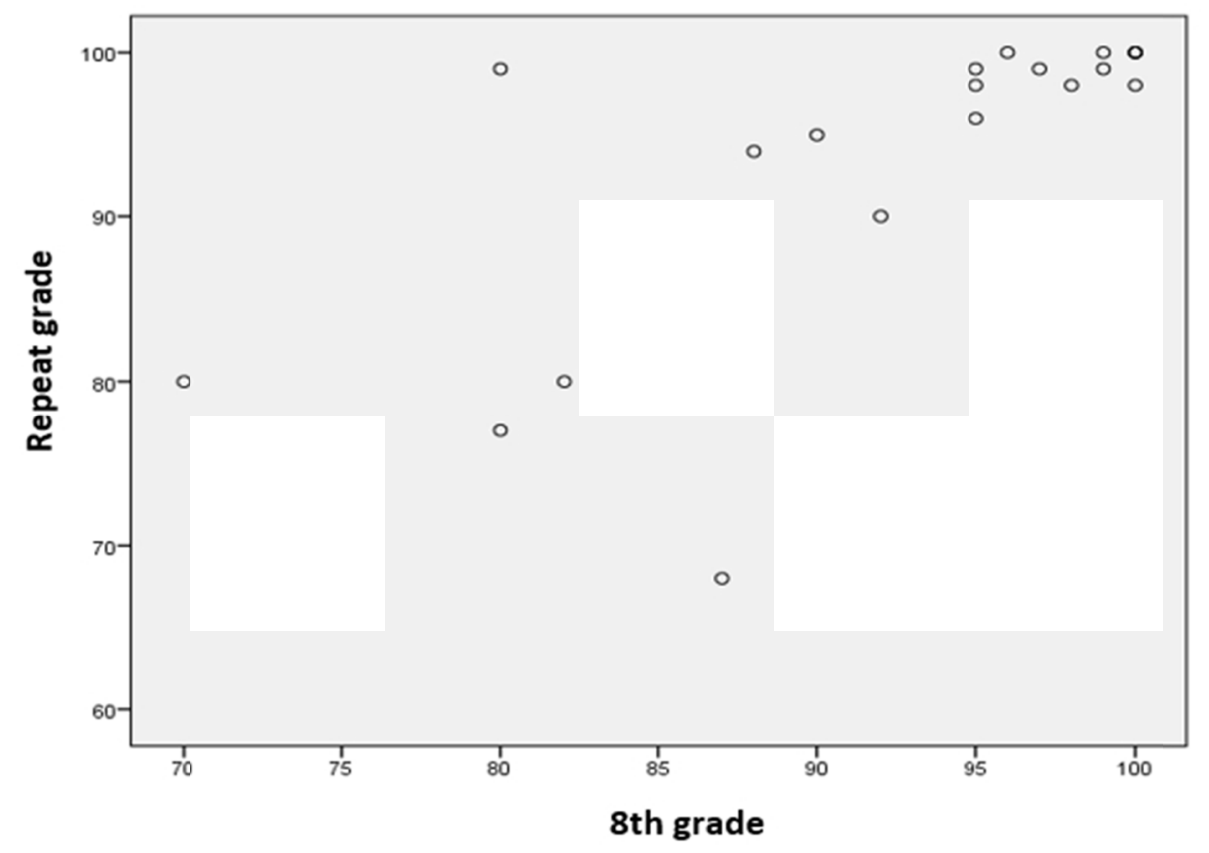

Figure 2. Correlation of the 8th and the follow-up rating scores of the students in the experimental group

For analyzing research data obtained from the rubrics and the scores of students, we conducted a comparison of the $8^{\text {th }}$ measurement and the follow-up score, measured one week after the experiment, to the experimental group students to determine the degree of sustainability of the information gained from the educational process. The comparison of the differences in the averages of the two scores of the students in the experimental group was made by the non-parametric statistical criterion for dependent samples - multiple Wilcoxon measurements (because the values of the gradient variables do not follow the normal distribution, Shapiro-Wilk sig. $<.050$ ).

The data analysis shows that the repeat scores (93.50) of the students in the experimental group are better than those of the 8th measurement (92.15). In particular, ten [10] scores were improved, five [5] remained stable and only five [5] deteriorated $(\mathrm{Z}(20)=-1.395, \mathrm{~ns})$. Also, from the correlation index $(\mathrm{r}=$ Pearson's $.707, \mathrm{p}=.000)$ we find that the high scores of the 8 th measurement remained high after the iterative rating, similar to the lower scores, which remained low in the second measurement.

The following Table 5 shows the averages of the scores of the two groups in the eight independent measurements.

Table 5. Comparison of the scores of the two groups in the eight iterative tests

\begin{tabular}{ccc}
\hline Score & Group & Average Score \\
\hline \multirow{2}{*}{$1^{\text {st }}$ score } & Experimental & 87.75 \\
& Control & 77.56 \\
$2^{\text {nd }}$ score & Experimental & 88.60 \\
& Control & 86.74 \\
$3^{\text {rd }}$ score & Experimental & 95.05 \\
& Control & 85.00 \\
\multirow{2}{*}{ Control } & Experimental & 90.30 \\
& Control & 75.20 \\
$5^{\text {th }}$ score & Experimental & 89.15 \\
& Control & 87.37 \\
$6^{\text {th }}$ score & Experimental & 89.25 \\
& Control & 87.61 \\
$7^{\text {th }}$ score & Experimental & 82.95 \\
& Control & 81.50 \\
$8^{\text {th }}$ score & Experimental & 92.15 \\
& Control & 79.35 \\
\hline
\end{tabular}




\section{Discussion}

Regarding the contribution of the electronic portfolio to the improvement pupils' performance and retaining their knowledge, from the results of the research and specifically from the scores in the eight repeat student tests, there are differences among the percentages in favor of the experimental group. More specifically, the data analysis shows that all eight scores of pupils in the experimental group are higher than those of the control group. Although the differences are not statistically significant in some scores, it clearly shows the differentiation in favor of the experimental group and this is a finding that confirms the positive contribution of e-portfolios to improving student performance and knowledge acquisition. These findings are also in accordance with the relevant literature, according to which through the electronic portfolio, the didactic-learning process is adapted to the learner's needs, interests, peculiarities and skills. Students have the ability to collect and organize digitally the objects of their work, which they can use to show their efforts, progress, aspirations and achievements over time, to reflect on their learning and improve their performance (Love \& Cooper, 2004; Abrami \& Barrett, 2005). Also, these findings are reinforced by a relative research's results, according to which the use of e-portfolio as a means of assessment in primary education allows the teachers to have clearer information on student progress, addressing their weaknesses and better planning the teaching on their behalf, thus, helping to upgrade and improve the performance of students (Kouloumparitsi \& Matsagouras, 2004). Additionally, it is argued that by collecting and evaluating their performance, learners can form an overall image of themselves on their own, since this portfolio contains their "qualitative characteristics" from their knowledge, activities and learning experiences and at the same time they reinforce self-confidence and knowledge, since they take control of their learning (Sherry \& Barrett, 2005). Moreover, the findings of this experiment are consistent with the findings of relevant researches, according to which, the electronic portfolio contributes to improving the quality of the learning process and to retaining knowledge as it is accessible by the pupil at all times and feedback is given immediately. Consequently, it promotes group learning, and reinforces the student-centered learning process, strengthens the feedback process, the exchange of views, assessment and self-assessment and contributes to the development of students' communication skills (Abrami \& Barrett, 2005). Finally, the findings of our research agree with relevant research findings, according to which the use of ICT in teaching in primary schools contributes to the preservation of the knowledge acquired by the students (Paraskevopoulos, Bilia, \& Paraskevopoulou, 2010), with the new technologies to promise a radical and total change in the way students learn, making the computer a powerful tool in a child's cognitive development (Raptis \& Rapti, 2001).

\section{Conclusions}

Based on the findings of this research and the above analysis we can draw the following conclusions:

Regarding the contribution of the e-portfolio to improving students' performance as well as the sustainability of their knowledge, it is noted that the students of the experimental group who utilized the electronic portfolio scored the highest ratings and managed to maintain the knowledge they gained by achieving higher grades in the second test conducted fifteen days later, compared to the students of the control group whose achievements were documented with the printed portfolio, achieving lower A scores in the examination. Additionally, this finding shows that new technologies promise a radical and total change in the way students learn. The modern society, the knowledge society, dictates the need to change and reform the educational system by using a computer, making it a powerful tool in the cognitive development of children.

This thesis also involves some noteworthy limitations. As far as the sample of the survey is concerned, there were pupils of the second grade of primary school and consisted of 40 people. The electronic portfolio only contained assessments of the Greek language course. There has been a time constraint on the implementation of this intervention, which has not allowed its further duration.

Therefore, a future conduction of this or a similar research could be held in the duration of the entire school year, in all school subjects and in all classes of the primary school.

Another direction that could be implemented in a future research would be to create e-portfolios in all classes of primary school starting from the first, to determine the contribution of the e-portfolio in the assessment and development of students' metacognitive skills. It is also important to investigate the reasons why the e-portfolio is not used by teachers in Greek primary education.

\section{References}

Abrami, P., \& Barrett, H. (2005). Directions for research and development on electronic portfolios. Canadian Journal of Learning and Technology, 31(3), 1-15.

Andreadakis, N. (2006). Portfolio-based Assessment [University Notes]. University of Crete, Department of 
Primary Education, Academic year 2005-2006. Rethymno.

Barrett, H. C. (2000). Researching electronic portfolios and learner engagement: The REFLECT initiative. Journal of Adolescent \& Adult Literacy, 50(6), 436-449. https://doi.org/10.1598/jaal.50.6.2

Barrett, H., \& Knezek, D. (2003). E-portfolios: Issues in assessment, accountability and preservice teacher preparation. Retrieved from https://eric.ed.gov/?id=ED476185

Brown, D. (1998). New Ways of Classroom Assessment, revised. TESOL Press.

Canada, M. (2002). Evaluating e-folios in the online class. New Directions for Teaching and Learning, 91, 69-75.

Challis, D. (2005). Towards the mature e-portfolio: Some implications for higher education. Canadian Journal of Learning and Technology, 31(3). Retrieved from https://www.learntechlib.org/d/43166

Coutinho, C., \& Bottentuit, J. (2008). The use of Web 2.0 tools to develop e-portfolios in a teacher training program: An exploratory survey. https://repositorium.sdum.uminho.pt/bitstream/1822/8554/1/icetpdf.pdf

Fotopoulou, C. (2012). E-portfolio as an educational tool in Secondary Education (Diploma Thesis). Piraeus: University of Piraeus.

Galanou, A. (2007). Student Electronic Portfolio e-portfolio (Diploma Thesis). Piraeus: University of Piraeus.

Health, M. (2005). Are you ready to go digital? The pros and cons of electronic portfolio development. Library Media Connection, 23(7), 66-70.

Knight, E., Hakel, D., \& Gromko, M. (2006). The Relationship between Electronic Portfolio Participation and Student Success. Retrieved from 15/02/2018 from: https://eric.ed.gov/?id=ED493824

Kouloubaritsi, X., \& Matsagouras, H. (2004). Student portfolio (portfolio assessment): The authentic assessment in the interdisciplinary teaching. In Angelidis, \& Mavroidis (Eds.), Educational Innovations for the School of the Future (pp.55-83). Athens: Dardanos (tipothito) editions.

Linn, R. L., \& Gronlund, N. E. (2000). Measurement and Assessment in Teaching.

Love, T., \& Cooper, T. (2004). Designing online information systems for portfolio-based assessment: Design criteria and heuristics. Journal of Information Technology Education, 3, 65-81. https://doi.org/10.28945/289

Paraskevopoulos, M., Bilia, A., \& Paraskevopoulou, P. (2010). Proceedings of the Hellenic Institute of Applied Education and Training (Hellenic Institute of Applied Pedagogy and Education). 5th Panhellenic Conference on Learning How to Learn, May 7-9, 2010.

Paroutsas, D. (2011). The Student Worksheet/Portfolio as a means of authentic assessment in Primary Education (Diploma Thesis). Patras: Greek Open University.

Raptis, A., \& Rapti, A. (2001). Learning and teaching in the age of information. Volume A, Athens.

Ritzhaupt, A., Singh, O., \& Seyferth, T. (2008). Development of the Electronic Portfolio Student perspective: an e-portfolio integration initiative. Journal of Computing in Higher Education, 19(2), 47-71. https://doi.org/10.1007/bf03033426

Ryan, C. (1994). Authentic Assessment. Teacher Created Materials Inc., USA.

Sherry, A. C., \& Barrett, A. (2005). Worth of electronic portfolios on education majors: A 'two by four'

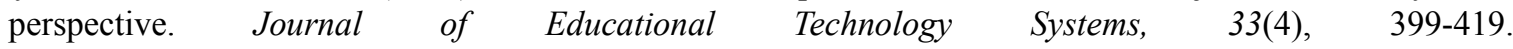
https://doi.org/10.2190/fccm-et90-fpdj-040f

Siemens, G. (2004). e-portfolios. eLearnSpace: Everything ELearning. Retrieved from http://www.elearnspace.org/Articles/e-portfolios.htm

Strudler, N., \& Wetzel, K. (2005). The diffusion of electronic portfolios in teacher education: Issues of initiation and implementation. Journal of Research on Technology in Education, 37, 411-433. https://doi.org/10.1080/15391523.2005.10782446

Stylianou, M. (2013). E-portfolio Assessment (Diploma Thesis). Nicosia: Open University of Cyprus.

Tsagari, D. (2011). Investigating the 'assessment literacy' of EFL state school teachers in Greece. In D. Tsagari, \& I. Csépes (Eds.), Classroom-based language assessment (pp. 169-190).

Tsoutstou, D., \& Bertsou, S. (2013). An Experimental Study on the Utilization of the E-Portfolio in Primary 
Education. Retrieved from https://e-portfoliogr.weebly.com/uploads/2/1/0/4/21044446/dt_sm_e-portfolios. pdf

Wade, A., Abrami, C., \& Sclater, J. (2005). An electronic portfolio to support learning. Canadian Journal of Learning and Technology, 31(3). Retrieved from http://files.eric.ed.gov/fulltext/EJ1073692.pdf

Young, J. R. (2002). E-portfolios could give students a new sense of their accomplishments. Chronicles of Higher Education, 48(26), A31-A32.

\section{Copyrights}

Copyright for this article is retained by the author(s), with first publication rights granted to the journal.

This is an open-access article distributed under the terms and conditions of the Creative Commons Attribution license (http://creativecommons.org/licenses/by/4.0/). 